\title{
Clozapine versus placebo in Huntington's disease: a double blind randomised comparative study
}

\author{
J P P van Vugt, S Siesling, M Vergeer, E A van der Velde, R A C Roos
}

\begin{abstract}
Objectives-To establish the effect of the atypical neuroleptic clozapine on chorea, voluntary motor performance, and functional disability in patients with Huntington's disease.

Methods-Thirty three patients with Huntington's disease participated in a double blind randomised trial. A maximum of $150 \mathrm{mg} /$ day clozapine or placebo equivalent was given for a period of 31 days. Assessments were performed in the week before and at the last day of the trial. Chorea was scored using the abnormal involuntary movement scale (AIMS), the chorea score of the unified Huntington's disease rating scale (UHDRS), and judgement of video recordings. Voluntary motor performance was assessed using the UHDRS motor scale. Patients and their partners completed a questionnaire regarding functional disability. Twelve patients already used other neuroleptic medication, which was kept unchanged during the trial period. Results of neuroleptic naive and neuroleptic treated patients were analysed separately.
\end{abstract}

Results-Clozapine tended to reduce chorea in neuroleptic naive patients only (AIMS); improvement seemed more pronounced in patients receiving higher doses of clozapine. Other measures of chorea (UHDRS chorea score, video ratings) showed no improvement. Clozapine had no beneficial effect on chorea in patients already receiving neuroleptic medication. Voluntary motor performance did not improve with clozapine. Neuroleptic naive patients reported aggravation of functional disability, possibly reflecting the frequent occurrence of side effects. Adverse reactions forced trial termination in six patients and dose reduction in another eight, and consisted mainly of drowsiness, fatigue, anticholinergic symptoms, and walking difficulties.

Conclusions-Clozapine has little beneficial effect in patients with Huntington's disease, although individual patients may tolerate doses high enough to reduce chorea. Because adverse reactions are often encountered, clozapine should be used with restraint in this patient group.

(F Neurol Neurosurg Psychiatry 1997;63:35-39)

Keywords: Huntington's disease; neuroleptic treatment; clozapine
Treatment of patients with Huntington's disease is aimed at reducing behavioural, psychiatric, and motor symptoms. Neuroleptic drugs are most commonly used for the treatment of chorea, but results have been rather disappointing. Although most classic neuroleptic drugs reduce chorea, ${ }^{1-3}$ these drugs fail to improve functional capacity $^{14}$ or even aggravate disability. ${ }^{5}$ The inability of classic neuroleptic drugs to improve functional capacity, despite ameliorating chorea, is conceivably due to suppression of voluntary motor activity. ${ }^{267}$ Furthermore, tardive dyskinesia has occasionally been reported in patients with Huntington's disease treated with classic neuroleptic drugs. ${ }^{6}$ The atypical neuroleptic clozapine, which in psychiatry is used for schizophrenic patients not responsive to classic neuroleptic drugs, ${ }^{9}$ has an extremely low incidence of extrapyramidal side effects ${ }^{10}$ and might thus be favourable in the treatment of chorea. Indeed, two previous reports seemed promising, but results were inconclusive because of small patient numbers or lack of placebo control. ${ }^{11}{ }^{12}$ Other investigators failed to find a pronounced effect of clozapine on chorea in Huntington's disease. ${ }^{1314}$ Therefore, we conducted a double blind placebo controlled trial in 33 patients with Huntington's disease, in which we analysed the effects of clozapine on chorea, voluntary motor performance, and functional disability.

\section{Patients and methods}

PATIENTS AND TRIAL DESIGN

Thirty three patients from our outpatient department with clinically and genetically established Huntington's disease and typical choreatic movements participated in the trial. Informed consent was obtained from all patients. Twelve patients (three men; mean age 54.7 (range 42-73) years; mean duration of disease 11.7 (range 4.8-25.8) years) were on neuroleptic medication, which remained unchanged during the trial. Neuroleptic drugs used were pimozide (five patients), tiapride (three), sulpiride (two), zuclopentixol (two), haloperidol (one), pipamperon (one), and perphenazine (one). The remaining 21 patients (12 men; mean age 44.8 (range 26-61) years; mean disease duration 8.1 (range 2.7-24.0) years) were neuroleptic-naive. Demented or psychotic patients, as well as patients with a history of clozapine use, were excluded from the trial.

Clozapine or placebo was randomly assigned to the patients by the hospital pharmacist, who was not involved in the assessment of the 
patients. Both the patient and the clinician remained blind to the treatment until all patients had completed the trial. Treatment covered a period of 31 days. Clozapine or placebo equivalent was started at $25 \mathrm{mg} /$ day and increased every other day, following a generally accepted schedule leading to satisfactory benefit/risk ratios and compliance in schizophrenic patients..$^{18}$ Dosage was increased until a predefined maximum $150 \mathrm{mg} /$ day was reached or side effects prevented further increase. This maximum dose was chosen because (1) Bonuccelli et $a l^{12}$ noted pronounced reduction of chorea by clozapine at $150 \mathrm{mg} /$ day, and (2) higher doses were expected to produce more adverse reactions. ${ }^{1018} 19$ Treatment was divided in four daily doses, with the larger dose given at the end of day to minimise the risk of daytime somnolence.

\section{ASSESSMENT OF TREATMENT EFFECTS}

Assessments were performed four days before and on the last day of the trial period, for every patient at the same time of day. Chorea was clinically rated by one of us (RACR) with the abnormal involuntary movement scale (maximum score: 36$)^{15}$ as well as the UHDRS chorea score (maximum score: 28). ${ }^{16}$ Furthermore, video recordings were made under standard conditions from all patients while sitting as relaxed as possible in a chair for one minute. For every patient, the two recordings, before and at the end of the trial, were randomly mixed by a technician and blindly judged by two of us (JPPV and RACR). Consensus was reached for global differences in severity of chorea between the two video fragments. After breaking the treatment code, these global judgements were translated in terms of improvement, worsening, or no change in chorea with therapy compared with baseline.

To study the effects of clozapine on voluntary motor performance, the following items of the UHDRS motor assessment ${ }^{16}$ were used: dysarthria, tongue protrusion, finger tapping, rapid alternating movements, Luria's fist-edgepalm test, rigidity, bradykinesia, gait, tandem walking, and postural stability (retropulsion). The sum score of this assessment was used for analyses (maximum score 40).

Under supervision of one of us (JPPV) patients completed a questionnaire which consisted of 21 items regarding daily activities. The questionnaire was a modification of a list validated by Brown et $a l^{17}$ to rate functional disability in patients with Parkinson's disease. On a five point scale, patients indicated whether they could perform the activity without difficulty (0 points), with some difficulty, with great difficulty, only with help, or not at all (4 points; maximum total score 84 ). If possible, partners were asked to complete the questionnaire regarding the patient's performance as well. At the end of the trial, patients and partners completed the same questionnaire to judge performance during the last week of the trial. Furthermore, patients were asked whether in general they had felt better, worse, or unchanged during the last week of the trial compared with before the trial.

ADVERSE REACTIONS

The occurrence of side effects was closely monitored by an investigator not involved in the clinical assessments of the patients but nevertheless blind to the treatment (SS). Patients could approach the investigator by telephone in case of possible side effects and all patients were contacted at day 10 of the trial. Guided by the occurrence and severity of possible side effects, the individual optimum daily dose of clozapine or placebo equivalent was determined. If appreciable side effects occurred, doses were either reduced and kept at a lower level or increased more slowly. In all patients, the daily dose was kept constant during the last 21 days of the trial. Blood samples were monitored weekly for changes in liver enzymes and white blood cell count by SS, who decided on trial suspension whenever predefined out of range values were noted. To guarantee blind assessment of outcome measures, blood laboratory values and the occurrence of side effects remained unknown to the other investigators. At the end of the trial, patients were specifically asked for the occurrence of all known side effects of clozapine. ${ }^{1018} 19$

\section{STATISTICAL ANALYSES}

Results were analysed for neuroleptic naive and neuroleptic treated patients separately to reduce any confounding influence of concomitant neuroleptic medication. Patients in whom severe adverse reactions had forced breaking of the treatment code were excluded from further analyses. Student's $t$ tests were used to show pretrial differences between the clozapine and placebo groups in any of the variables. Treatment effects were evaluated by calculating the differences between scores before and at the end of the trial. These differences were compared between placebo and clozapine using analysis of covariance (ANCOVA), taking baseline scores into account to minimise the effect of pretrial between group disparities. Because multiple variables were tested, P values $<0.01$ were regarded as indicative of significant differences.

\section{Results}

BASELINE COMPARISON

In seven patients, trial suspension was necessary. These patients did not differ significantly from those who completed the trial in any of the variables studied (Student's $t$ test), and were excluded from further analyses. From the 26 patients who completed the trial, eight used neuroleptic medication whereas the remaining 18 were neuroleptic naive. Results of neuroleptic naive and neuroleptic treated patients were analysed separately. To show any pretrial differences between the clozapine and placebo groups, baseline values of the test variables were compared by Student's $t$ tests. In neuroleptic free patients the clozapine group tended to have more chorea than the placebo group $(P=0.04)$, whereas in neuroleptic treated patients the placebo group scored 
Table 1 Mean (SD) baseline values

\begin{tabular}{|c|c|c|c|c|}
\hline & \multicolumn{2}{|c|}{ Neuroleptic naive } & \multicolumn{2}{|c|}{ Neuroleptic treated } \\
\hline & $\begin{array}{l}\text { Clozapine } \\
(n=7)\end{array}$ & $\begin{array}{c}\text { Placebo } \\
(n=11)\end{array}$ & $\begin{array}{l}\text { Clozapine } \\
(n=4)\end{array}$ & $\begin{array}{l}\text { Placebo } \\
(n=4)\end{array}$ \\
\hline Age $(y)$ & $43.6(11.4)$ & $44.4(10.6)$ & $50.5(7.9)$ & $56.5(3.9)$ \\
\hline Disease duration (y) & $9.3(7.5)$ & $7.3(3.0)$ & $7.3(3.8)$ & $15.3(7.4)$ \\
\hline AIMS & $18.7(6.3)$ & $13.4(4.2)$ & $20.3(8.5)$ & $23.5(5.1)$ \\
\hline UHDRS Chorea score & $13.1(4.9)$ & $10.3(1.0)$ & $16.5(4.2)$ & $17.8(2.5)$ \\
\hline UHDRS Voluntary movements & $23.7(7.4)$ & $17.4(8.9)$ & $30.3(8.1)$ & $39.5(5.8)$ \\
\hline Self evaluated disability & $17.7(13.5)$ & $16.9(21.7)$ & $34.3(4.9)$ & $50.0(2.0)^{\star}$ \\
\hline Partner evaluated disability & $22.9(17.4)$ & $12.5(10.6)$ & $48.5(14.5)$ & $53.8(12.6)$ \\
\hline
\end{tabular}

${ }^{\star} \mathrm{P}<0.01$ (Student's $t$ test). AIMS=Abnormal involuntary movements scale; UHDRS=unified Huntington's disease rating scale.

Table 2 Treatment effects (ANCOVA)

\begin{tabular}{|c|c|c|c|c|c|c|}
\hline & \multicolumn{3}{|c|}{ Neuroleptic naive } & \multicolumn{3}{|c|}{ Neuroleptic treated } \\
\hline & $\begin{array}{l}\text { Clozapine } \\
(n=7)\end{array}$ & $\begin{array}{l}\text { Placebo } \\
(n=11)\end{array}$ & $\begin{array}{l}P \\
\text { value }\end{array}$ & $\begin{array}{l}\text { Clozapine } \\
(n=4)\end{array}$ & $\begin{array}{l}\text { Placebo } \\
(n=4)\end{array}$ & $P$ value \\
\hline AIMS & $-7.3(3.4)$ & $0(4.8)$ & 0.02 & $-3.0(7.2)$ & $-7.0(6.4)$ & 0.61 \\
\hline UHDRS Chorea score & $-4.0(3.0)$ & $-0.3(3.7)$ & 0.07 & $-4.5(5.4)$ & $-3.8(5.7)$ & 0.81 \\
\hline $\begin{array}{l}\text { UHDRS Voluntary } \\
\text { movements }\end{array}$ & $-3.4(2.6)$ & $-0.5(4.8)$ & 0.44 & $-0.8(5.6)$ & $-0.8(2.1)$ & 0.82 \\
\hline Self evaluated disability & $5.7(9.2)$ & $-3.8(7.7)$ & 0.02 & $2.3(6.4)$ & $-0.3(16.2)$ & 0.83 \\
\hline $\begin{array}{l}\text { Partner evaluated } \\
\text { disability }\end{array}$ & $4.6(5.0)$ & $3.7(4.6)$ & 0.78 & $2.5(5.9)$ & $-2.0(4.3)$ & 0.34 \\
\hline
\end{tabular}

Values represent mean differences (SD) between 2nd and 1st assessment. Positive values indicate worsening with treatment. AIMS=Abnormal involuntary movements scale; UHDRS=unified Huntington's disease rating scale.

Table 3 Global judgements (number of patients (\%))

\begin{tabular}{|c|c|c|c|c|}
\hline & \multicolumn{2}{|c|}{ Neuroleptic naive } & \multicolumn{2}{|c|}{ Neuroleptic treated } \\
\hline & $\begin{array}{l}\text { Clozapine } \\
(n=7)\end{array}$ & $\begin{array}{l}\text { Placebo } \\
(n=11)\end{array}$ & $\begin{array}{l}\text { Clozapine } \\
(n=4)\end{array}$ & $\begin{array}{l}\text { Placebo } \\
(n=4)\end{array}$ \\
\hline \multicolumn{5}{|c|}{ Video rating of choreatic movements: } \\
\hline Worse & - & $1(9)$ & $2(50)$ & $2(50)$ \\
\hline Unchanged & $4(57)$ & $5(45)$ & $1(25)$ & $1(25)$ \\
\hline Improved & $3(43)$ & $5(45)$ & $1(25)$ & $1(25)$ \\
\hline \multicolumn{5}{|c|}{ Patient's judgement of last trial week: } \\
\hline Worse & $2(29)^{\star}$ & $1(9)$ & $1(25)^{\star}$ & $2(50)$ \\
\hline Unchanged & $2(29)$ & $6(55)$ & $2(50)$ & $1(25)$ \\
\hline Improved & $3(43)$ & $4(36)$ & $1(25)$ & $1(25)$ \\
\hline
\end{tabular}

^Four patients (two neuroleptic naive, two neuroleptic treated) experienced subjective complaints severe enough to force trial suspension (see table 4). Correcting the presented figures for their judgements, $44 \%$ of neuroleptic naive and $50 \%$ of neuroleptic treated patients would judge the last week of the trial as worse.

significantly worse on functional disability $(\mathrm{P}<$ $0.01)$. No pretreatment differences were found in any of the other test variables (table 1).

TREATMENT EFFECTS IN NEUROLEPTIC NAIVE AND NEUROLEPTIC TREATED PATIENTS

Because pretreatment differences would frustrate an unequivocal interpretation of treatment effects, ANCOVA was used to investigate the effects of clozapine and placebo, taking pretreatment values into account as covariate.

For neuroleptic naive patients, chorea tended to be reduced by clozapine (AIMS and UHDRS chorea score; table 2). Video recordings were judged as uninfluenced by medication in $57 \%$ of patients treated with clozapine, compared with $46 \%$ of placebo treated patients. Reduction of chorea was found in $43 \%$ with clozapine and $46 \%$ with placebo (table 3 ). No differences in voluntary motor performance were found between clozapine and placebo treated patients (table 2). Self evaluated disability was aggravated by clozapine compared with placebo, although this was not confirmed by ratings made by partners
Table 4 Severity of adverse effects (number of patients)

\begin{tabular}{|c|c|c|}
\hline & $\begin{array}{l}\text { Clozapine } \\
(n=17)\end{array}$ & $\begin{array}{l}\text { Placebo } \\
(n=16)\end{array}$ \\
\hline $\begin{array}{l}\text { No adverse effects } \\
\text { Mild (no consequences) } \\
\text { Moderate (dose reduction } \\
\text { necessary) } \\
\text { Severe (trial suspension } \\
\text { necessary) }\end{array}$ & $\begin{array}{l}- \\
8+\end{array}$ & $\begin{array}{l}11^{\star} \\
4\end{array}$ \\
\hline
\end{tabular}

^Trial suspension forced by intercurrent illness in one patient. †Reason for dose reduction (number of patients): drowsiness (three); confusion (one); urinary incontinence (one); walking difficulties (one); dizziness (one); increased liver enzymes (one). $\ddagger$ Reason for trial suspension (number of patients): urinary incontinence (one); walking/speaking difficulties (one); orthostatic hypotension/syncope (one); increased liver enzymes (two); epileptic seizure (one).

(table 2). When patients were asked how they in general judged the last trial week, $29 \%$ of the neuroleptic naive patients had felt worse with clozapine, compared with $9 \%$ of the placebo group (table 3).

In neuroleptic treated patients, clozapine had no significant influence on any of the test variables compared with placebo (ANCOVA, table 2). Results of global video judgements and patient's opinion of the last trial week are difficult to interpret because of the few patients in this group (table 3).

Side effects had prevented increase of clozapine dose to the predefined maximum of 150 $\mathrm{mg} /$ day in most of the patients, which might have tapered the effect on chorea. We found more pronounced reduction of chorea in three patients receiving $150 \mathrm{mg} /$ day of clozapine. However, establishing a formal dose-effect relation was not the primary aim of our study, and patient numbers were too small to consider this issue statistically.

\section{ADVERSE REACTIONS}

When asked for the occurrence of adverse effects, all patients treated with clozapine claimed to have experienced some side effects (table 4). Reduction of clozapine dose was necessary in eight patients; individual optimum doses tolerated were $50 \mathrm{mg} /$ day (three patients), $75 \mathrm{mg} /$ day (one), $100 \mathrm{mg}$ /day (three), and $125 \mathrm{mg} /$ day (one). Another six patients were unable to complete the trial because of side effects (table 4). Side effects most often reported were drowsiness (14 patients), dizziness (six), walking difficulties (six), fatigue (four), and hypersalivation (four). In seven patients, clozapine induced increase in liver enzymes was seen, forcing dose reduction in one patient and trial suspension in two. Laboratory values returned to normal within four weeks after clozapine withdrawal. One patient experienced a generalised epileptic seizure while receiving clozapine at $150 \mathrm{mg} /$ day. Extensive history analysis showed no other cause for this epileptic seizure. After clozapine was withdrawn, no further seizures were experienced. In the placebo group, one patient could not complete the trial due to intercurrent illness.

\section{Discussion}

The results of this placebo controlled double blind randomised trial indicate that clozapine 
is of little use in the treatment of chorea in patients with Huntington's disease. Although clozapine tended to reduce chorea rated with the AIMS and the UHDRS chorea scale in neuroleptic free patients, especially in patients receiving higher doses of clozapine, the frequent occurrence of side effects prevented dose increase to the predefined maximum of 150 $\mathrm{mg} /$ day in most of the patients. Judgement of video recordings and assessment of voluntary motor performance showed no differences between clozapine and placebo. Moreover, patients reported more severe functional disability while receiving clozapine. Clozapine did not influence any of the variables in patients already receiving other neuroleptic medication.

Our findings corroborate the small effect of clozapine on chorea in patients with Huntington's disease noted by others. ${ }^{13}{ }^{14}$ Caine et a $l^{11}$ studied the effect of clozapine on various dyskinaesiae in a placebo controlled crossover trial, in which three patients with Huntington's disease participated. In their study, chorea was reduced in two patients at doses of $200 \mathrm{mg} /$ day and $500 \mathrm{mg} /$ day respectively, whereas the third patient with Huntington's disease failed to complete the trial due to confusion, slurred speech, and severe orthostatic hypotension. ${ }^{11}$ This is in keeping with our results showing considerable reduction of chorea in three patients who tolerated the predefined maximum dose of $150 \mathrm{mg} /$ day in the face of noticeable adverse reactions in other patients. The results of our study largely contradict the findings of Bonuccelli et al, ${ }^{12}$ who noted a striking reduction of chorea (without significant side effects) at clozapine doses as low as $50 \mathrm{mg}$ /day in an open label trial conducted on five patients with Huntington's disease. Possibly, their dose schedule $(25 \mathrm{mg} /$ day in week $1,50 \mathrm{mg} /$ day in week 2 , and $150 \mathrm{mg} /$ day in week 3) might be favourable with regard to side effects, although some of our patients did not even tolerate 50 $\mathrm{mg} /$ day at day 10. Nevertheless, the discrepancy between the findings of Bonuccelli et $a l^{12}$ and the results of the present study underscores the need for placebo control in the evaluation of possible therapeutic agents.

The limited effect of clozapine on chorea might be explained by its relatively low D2 dopaminergic antagonistic properties. D2 receptor containing striatal projection neurons towards the external pallidal segment are involved in an indirect cortical-basal ganglialcortical feedback loop which is normally active in the suppression of involuntary motor activity. ${ }^{20-23}$ Preferential loss of these neurons is thought to be the pathophysiological basis of chorea in patients with Huntington's disease. ${ }^{24-26}$ Nigrostriatal dopaminergic input yet further inhibits activity of this striatal cell population, ${ }^{20}{ }^{22}$ which is probably why D2 antagonising agents ameliorate chorea. ${ }^{7}$ Both in vitro and in vivo studies have shown the low affinity of clozapine for D2 receptors compared with classic neuroleptic compounds, ${ }^{27-29}$ conceivably limiting its antichoreic potencies in Huntington's disease. The intrinsic anticholinergic properties of clozapine might even counteract a reduction of chorea in patients with
Huntington's disease, ${ }^{30}$ possibly by blockade of acetylcholine mediated stimulation of striatal projection neurons towards the external pallidal segment. ${ }^{20} 22$

D2 receptor occupancy rises when higher doses of clozapine are administered, ${ }^{27}$ which might explain our finding that reduction of chorea seemed more pronounced in patients receiving higher doses. This is also in keeping with the reduction of chorea in two patients with Huntington's disease treated with high doses of clozapine noted by Caine $e t a l^{11}$, as well as with the dose-effect relation reported by Bonuccelli et al. ${ }^{12}$

The frequent occurrence of side effects can explain why more patients felt worse with clozapine than with placebo, as well as why self evaluated disability tended to worsen. Our findings corroborate earlier reports regarding side effects in patients with Huntington's disease treated with clozapine. Caine et al noted significant adverse reactions in all their patients, compromising the patients' functioning and "ability to perform routine self care tasks". ${ }^{11}$ Pronounced sedation of most patients with Huntington's disease was described by Colosimo et al, even at clozapine doses as low as $25 \mathrm{mg} /$ day. ${ }^{14}$ In this respect, the absence of any significant side effect as reported by Bonuccelli et $a l^{12}$ seems unusual. Patients with organic brain disease seem to be more prone to adverse reactions of clozapine, ${ }^{18}$ so special care should be taken in this patient group.

In conclusion, there seems to be little place for clozapine in the treatment of chorea in patients with Huntington's disease. Clozapine only tended to reduce chorea in patients not using other neuroleptic medication, whereas functional disability seemed worsened. The frequent occurrence of, in some cases severe, adverse reactions probably underlies the second finding. Some individual patients tolerated clozapine at doses high enough to reduce chorea. Future studies might consider early identification of these responders and the value of alternative dose schedules. Based on the data available at present, clozapine should be used with reserve in patients with Huntington's disease.

We thank the patients and their family physicians who participated in this study. We are grateful to Sandoz BV and specifically to JCMJ Stokvis who kindly provided the medication for this study. Drs HCR Brandenburg from the Leiden Univer-
sity Hospital Pharmaceutical Department is gratefully acknowledged for performing the randomisation procedure. We are indebted to Gerard van de Giessen who patiently recorded and mixed the video fragments, and to Ad Jansen for technical assistance.

1 Quinn N, Marsden CD. A double blind trial of sulpiride in Huntington's disease and tardive dyskinesia. $f$ Neurol Neurosurg Psychiatry 1984;47:844-7.

2 Girotti F, Carella F, Scigliano G, et al. Effect of neuroleptic treatment on involuntary movements and motor performances in Huntington's disease. $f$ Neurol Neurosurg Psychiatry 1984;47:848-52.

3 Deroover J, Baro F, Bourguignon RP, Smets P. Tiapride versus placebo: a double-blind comparative study in the management of Huntington's chorea. Curr Med Res Opin 1984; 9:329-38.

4 Feigin A, Kieburtz K, Bordwell K, et al. Functional decline in Huntington's disease. Mov Disord 1995;10:211-4.

5 Shoulson I. Huntington's disease: functional capacities in Shoulson I. Huntington's disease: functional capacities in
patients treated with neuroleptic and antidepressant drugs. patients treated with neurolept

6 Shoulson I. Care of patients and families with Huntington's disease. In: Marsden CD, Fahn S, eds. Movement disorders. London: Buttersworth, 1982:277-90. 
7 Klockgether T, Dichgans J. Do neuroleptic drugs still have a place in neurological therapy? F Neurol 1990;237:221-5.

8 Schott K, Ried S, Stevens I, Dichgans J. Neuroleptically induced dystonia in Huntington's disease: a case report Eur Neurol 1989;29:39-40.

9 Kane J, Honigfeld G, Singer J, Meltzer H. Clozapine for the treatment-resistant schizophrenic. Arch Gen Psychiatry 1988;45:789-96.

10 Baldessarini RJ, Frankenburg FR. Clozapine-a novel antipsychotic agent. $N$ Engl $\mathcal{F}$ Med 1991;324:746-54

11 Caine ED, Polinsky RJ, Kartzinel R, Ebert MH. The trial use of clozapine for abnormal involuntary movemen disorders. Am f Psychiatry 1979;136:317-20.

12 Bonuccelli U, Ceravolo R, Maremmani C, Nuti A, Rossi G, Muratorio A. Clozapine in Huntington's chorea. Neurology 1994;44:821-3.

13 Sajatovic M, Verbanac P, Ramirez LF, Meltzer HY. Clozapine treatment of psychiatric symptoms resistant to neuroleptic treatment in patients with Huntington's chorea. Neurology 1991;41:156.

14 Colosimo C, Cassetta E, Bentivoglio AR, Albanese A. Clozapine in Huntington's disease [letter]. Neurology 1995 45:1023-4

15 AIMS. In: Guy W, ed. ECDEU assessment manual. Rockville, Maryland: US Department of Health, Education and Welfare 1976:534-7.

16 Huntington Study Group. The unified Huntington's disease rating scale: reliability and consistency. Mov Disord 1996;11:136-42.

17 Brown RG, MacCarthy B, Jahanshahi M, Marsden CD. Accuracy of self-reported disability in patients with parkinsonism. Arch Neurol 1989;46:955-9.

18 Naber D, Holzbach R, Perro C, Hippius H. Clinical management of clozapine patients in relation to efficacy and side-effects. Br F Psychiatry 1992;160(suppl 17): 54-9.
19 Jann MW, Grimsley SR, Gray EC, Chang W. Pharmacokinetics and pharmacodynamics of clozapine. Clin Pharmacokinet 1993;24:161-76.

20 Penney JB, Young AB. Striatal inhomogeneities and basal ganglia function. Mov Disord 1986;1:3-15.

21 Albin RL, Reiner A, Anderson KD, Penney JB, Young AB. Striatal and nigral neuron subpopulations in rigid Huntington's disease: implications for the functional anatomy of chorea and rigidity-akinesia. Ann Neurol 1990;27:357-65.

22 Alexander GE, Crutcher MD. Functional architecture of basal ganglia circuits: neural substrates of parallel processing. Trends Neurosci 1990;13:266-71.

23 Gerfen CR, Engber TM, Mahan LC, et al. D1 and D2 dopamine receptor-regulated gene expression of striatonigral and striatopallidal neurons. Science 1990;250:1429-32.

24 Reiner A, Albin RL, Anderson KD, D'Amato CJ, Penney JB, Young AB. Differential loss of striatal projection neurons in Huntington's disease. Proc Natl Acad Sci USA 1988;85:5733-7.

25 Crossman AR. Neural mechanisms in disorders of movement. Comp Biochem Physiol 1989;93A:141-9.

26 Storey E, Beal MF. Neurochemical substrates of rigidity and chorea in Huntington's disease. Brain 1993;116:1201-22.

27 Sedvall G. PET imaging of dopamine receptors in human basal ganglia: relevance to mental illness. Trends Neurosci 1990;13:302-8.

28 Farde L, Nordström A-L. PET analysis indicates atypical central dopamine receptor occupancy in clozapine-treated patients. Br f Psychiatry 1992;160(suppl 17):30-3.

29 Seeman P, Van Tol HHM. Dopamine receptor pharmacology. Trends Pharmacol Sci 1994;15:264-70.

30 Klawans HL. Chorea. Can f Neurol Sci 1987;14:536-40. 